\title{
Favorable Personality Traits in Women Who Have Undergone Cosmetic Breast Augmentation Surgery
}

(1) Güncel Öztürk¹, (1) Elmas Beyazyüz², (1) Yakup Albayrak², (1) Murat Beyazyüz²

${ }^{1}$ Department of Plastic Surgery, Nişantaşı University, İstanbul, Turkey

${ }^{2}$ Department of Psychiatry, Tekirdağ Namık Kemal University School of Medicine, Tekirdağ, Turkey

\begin{abstract}
Objective: Breast augmentation surgery is one of the most common cosmetic procedures among women. In the present study, we compared personality traits, self-esteem, and body perception between women who had undergone breast augmentation surgery and a control group of women who had not. We hypothesized that the personality traits of women who had vs those who had not undergone breast augmentation surgery would differ.

Materials and Methods: According to the inclusion and exclusion criteria, patients who had undergone breast augmentation surgery and age- and education-matched, healthy women were included in the present study. The breast augmentation group and control group were compared in terms of personality traits under the Basic Personality Traits Inventory. Additionally, self-esteem, which was assessed with the Rosenberg Self-Esteem Scale, and body perception, which was evaluated using the Body Cathexis Scale, were measured and compared between the two groups.

Results: When the patients $(n=80)$ and the control group $(n=100)$ were compared, the Body Cathexis Scale, extroversion, and openness scores were statistically significant and were found to be higher in the breast augmentation group ( $<<0.05)$. In regression analysis, it was found that age, openness, and the Rosenberg Self-Esteem Scale score had statistically significant effects on extroversion.

Conclusion: We argue that there may be a presupposition, based on stigma, that women who undergo breast augmentation surgery are more neurotic than those who do not. Consequently, this may influence the outcomes of studies evaluating the personalities of these women. Our results indicate that women who had undergone breast augmentation had more positive personality traits than women in an un-operated control group.
\end{abstract}

Keywords: Breast, augmentation, personality, cosmetic

Cite this article as: Öztürk G, Beyazyüz E, Albayrak Y, Beyazyüz M. Favorable Personality Traits in Women Who Have Undergone Cosmetic Breast Augmentation Surgery. Eur J Breast Health 2021; 17(4): 308-314.

\section{Key Points}

- Breast augmentation surgery is one of the most common cosmetic procedures among women.

- Data about personality traits in women who had undergone breast augmentation surgery are limited.

- The present study showed that the breast augmentation group had more positive personality traits than the control group.

\section{Introduction}

Breast augmentation surgery is one of the most common cosmetic procedures among women $(1,2)$. It is estimated that approximately 300,000 women undergo cosmetic breast augmentation annually in the United States alone (3). Several studies have found that breast augmentation has a positive impact on women in terms of improving self-esteem and depressive symptoms, getting having greater satisfaction with their breasts, enhancing body image, and increasing well-being (4-6). Despite the positive effects of breast augmentation on women's psychological state, surgeons must assess patients' motivations for surgery and determine their emotional status. Surgeons must determine that candidates do not have body dysmorphic disorder or unrealistic expectations before operating. Several studies have reported that women who undergo breast augmentation surgery are more likely to use tobacco and alcohol, as well as higher anxiety levels, and are more likely to have a neurotic personality $(7,8)$. It is vital that surgeons take these factors into consideration during preoperative patient assessment.

There has been much interest in the psychological status of women who undergo breast augmentation, but only a small number of studies have investigated personality traits among these patients. It has been well established that personality traits affect emotion, ideas, and behaviors (9). According to the Big Five Personality Traits, a high level of neuroticism is associated with higher levels of anxiety, as well as with affective 
disorders $(10,11)$. Extroversion is a characteristic of individuals with superior communication skills and a more positive outlook (12). People who have higher scores for "agreeableness" are considered to be tolerant, polite, and willing to share (12). People who have higher levels of conscientiousness are thought to be hardworking, tidy, and prudish. People with a high score for openness are described as productive, imaginative, and highbrow (13). Two studies have investigated changes in personality traits before and after breast augmentation surgery. In an earlier study, it was reported that women with breast augmentation surgery had a postoperative tendency to enter a neurotic state (14). However, in a more recent study, Zaborski et al. (2) demonstrated that breast augmentation surgery had no effect on levels of neuroticism.

In the present study, we compared personality traits, self-esteem, and body perception between women who underwent breast augmentation surgery and an unoperated control group. We hypothesized that personality traits would differ between women who underwent breast surgery operations and those who did not.

\section{Materials and Methods}

The study was performed in two centers. Patients were selected from the private clinic of one of the authors. To be included, patients were required to meet the following criteria: breast augmentation surgery for aesthetic purposes received at least one year earlier, education level sufficient to understand the assessment tools used in the study, and willingness to participate in the study. A senior psychiatrist (Y.A.) assessed the patients, either online or face-to-face, to determine the history or ongoing presence of psychiatric disorders. Patients who had been diagnosed with a psychiatric disorder, those who had a history of psychiatric disorders, and those who were not willing to participate in the study were excluded. Additionally, women who had chronic disease, those who had another cosmetic problem, and those whose Body Mass Index was greater than 25 or lower than 20 were also excluded from the study. Of 114 patients, 80 met the inclusion criteria. The control group was selected from among staff members of the university hospital. The staff members were consisted of medical doctors, nurses and medical school students. The exclusion criteria for the control group included having a psychiatric disorder or a history of psychiatric disorders, refusing inclusion in the study after receiving detailed information, having a chronic disease, having another cosmetic problem, and having a Body Mass Index greater than 25 or lower than 20. As in the patient group, senior psychiatrists assessed all candidates of the control group to determine a history or ongoing presence of psychiatric disorders. The control group consisted of 100 healthy subjects. The patient group and control group were matched in terms of age and education level. All procedures performed in studies involving human participants were in accordance with the ethical standards of the institutional and/or national research committee and with the 1964 Helsinki Declaration and its later amendments or comparable ethical standards. The study was approved by the Local Research Ethics Committee of the Non-Invasive Clinic Research. The study was approved by Tekirdağ Namık Kemal University NonInvasive Clinical Research Ethics Committee (date: 30.05.2019/ approval no: 2019.101.06.22).

All participants gave written informed consent before participating in the study. Additional permissions were obtained from patients whose clinical images were used in the present study.
Tools

\section{Basic Personality Traits Inventory}

The Basic Personality Traits Inventory was created by Gençöz and Öncül (15) in 2012, based on the Big Five Personality theory and used to measure personality traits. This inventory includes 45 items with a five-point Likert-type scale and six personality traits (15).

\section{Rosenberg Self-Esteem Scale}

The Rosenberg Self-Esteem Scale (RSES) was created by Rosenberg in 1965 , and the validity and reliability of the scale was confirmed by Çuhadaroğlu (17) in $1986(16,17)$. The first 10 items of the scale are used for the evaluation of self-esteem. A total score of $0-1$ on these items indicates high self-esteem, a total score of 2-4 indicates average self-esteem, and a total score of 5-6 indicates low self-esteem. Lower scores indicate higher levels of self-esteem (16).

\section{Body Cathexis Scale}

The Body Cathexis Scale (BCS) was created by Secord and Jourard (18) in 1953 and has 40 items. The items are ranked using a fivepoint Likert-type scale that ranges from 1, meaning I do not like at all, to 5, meaning I really like. One score is determined from the scale. The lowest possible score is 40 , the highest is 200 , and higher scores indicate more positive evaluations. The BCS vas validated into Turkish language by Hovardaoğlu (19).

\section{Statistical analysis}

Statistical analyses were performed using $\mathrm{R}$ version 3.5.3, SPSS Statistics, version 23.0 (IBM Corp., Armonk, NY, USA), and G*Power version 3.1.9.4. The normality assumption of parametric tests was tested with the Shapiro-Wilk test. When the assumption was satisfied, an independent-sample t-test was used to compare patients with the control group. The adequacy of the sample size was tested by a power analysis. Depending on the normality assumption for the correlation analysis, Pearson's coefficient of correlation was used. Step-wise multiple regression was applied to determine which potential dependent variables would affect the independent variables. This technique was also used to eliminate non-significant dependent variables. The following assumptions of the regression were checked: the relationship between the independent and dependent variables is linear, the mean of residuals is zero, the normality of residuals is accurate, there is no multicollinearity, there is no autocorrelation of residuals, and there are significant levels, at 0.05 , of homoscedasticity of residuals or equal variance value.

\section{Results}

In the power analysis, two independent-sample t-tests were used. Figure 1 shows that the total sample size of 30 already achieved $65.1 \%$ power with a significance level of 0.05 to detect an effect size of 0.9060 . In the study, a total sample size of 100 was determined, and the power was approximately $99 \%$.

The descriptive data of the participants are shown in Table 1. When the patient and control groups were compared, the BCS, extroversion, and openness scores were statistically significant and were found to be higher in the breast augmentation group (Table 2).

Figure 2 shows the correlation between the body BCS, RSES, extraversion, agreeableness, conscientiousness, neuroticism, openness, and negative valance. Overall, no significant correlations $(\mathrm{p}>0.05)$ were found between the body image scale score and neuroticism, the 
body image scale score and openness, extraversion and the BCS score, extraversion and conscientiousness, extraversion and negative valance, agreeableness and neuroticism, conscientiousness and openness, conscientiousness and neuroticism, openness and neuroticism, or openness and negative valance.

Significant correlations $(\mathrm{p}<0.05)$ were found in the control group (a) between RSES score and body image score, RSES score and neuroticism, RSES score and negative valance, BCS score and negative valance, extraversion and agreeableness, extraversion and openness, agreeableness and conscientiousness, openness and agreeableness, openness and conscientiousness and neuroticism and negative valance, and their correlations were positive ( $p=0.292-0.685)$. In the patient group (b), significant correlations $(\mathrm{p}<0.05)$ were found between RSES score and conscientiousness, conscientiousness and openness, and neuroticism and negative valance, and their correlations were also positive $(\mathrm{p}=0.332-0.451)$.

Multiple regressions were used to estimate extroversion and openness with two different models (Table 3) using the stepwise technique.

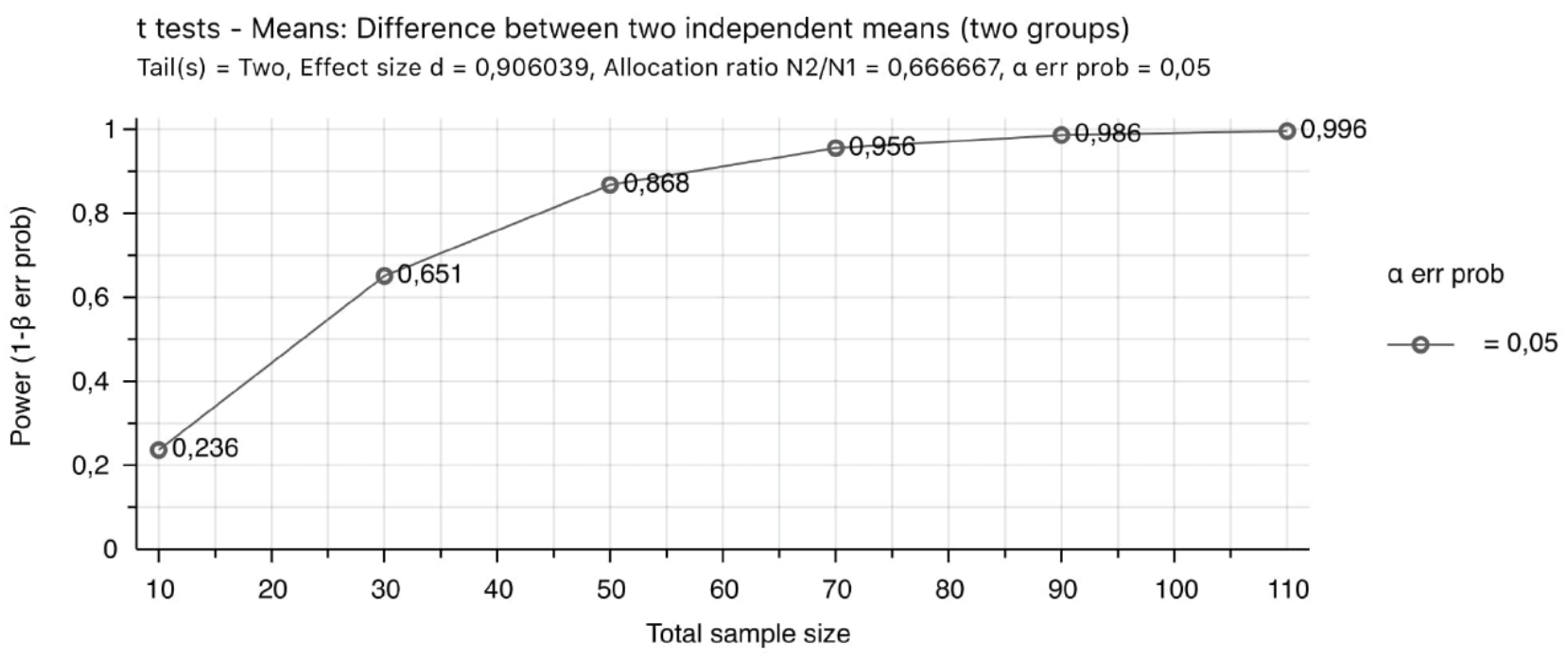

Figure 1. Power analysis

Table 1. Descriptive statistics

\begin{tabular}{|c|c|c|c|c|c|c|c|}
\hline & Categories & $\mathbf{n}$ & $\%$ & $\overline{\mathbf{x}}$ & s & Median & IQR \\
\hline \multirow{2}{*}{ Group } & Control & 120 & 60.0 & - & - & 1.00 & $1.00-2.00$ \\
\hline & Patients & 80 & 40.0 & - & - & - & - \\
\hline Age & - & - & - & 29.320 & 6.014 & 28.00 & $25.00-32.00$ \\
\hline Education (years) & - & - & - & 15.380 & 2.627 & 16.00 & $13.00-18.00$ \\
\hline \multirow{2}{*}{ Marital status } & Married & 68 & 34.0 & - & - & 2.00 & $1.00-2.00$ \\
\hline & Single & 132 & 66.0 & - & - & - & - \\
\hline \multirow{2}{*}{ Smoking } & Presence & 64 & 32.0 & - & - & 2.00 & $1.00-2.00$ \\
\hline & Absent & 136 & 68.0 & - & - & - & - \\
\hline \multirow{2}{*}{ Alcohol use } & Presence & 88 & 44.0 & - & - & 2.00 & $1.00-2.00$ \\
\hline & Absent & 112 & 56.0 & - & - & - & - \\
\hline Rosenberg's Self-Esteem Scale & - & 200 & - & 0.928 & 0.588 & 0.75 & $0.50-1.25$ \\
\hline Body Cathexis Scale & - & 200 & - & 98.900 & 34.633 & 89.00 & $80.00-123.75$ \\
\hline Extraversion & - & 200 & - & 32.260 & 5.485 & 32.50 & $29.00-35.00$ \\
\hline Agreeableness & - & 200 & - & 29.360 & 6.741 & 28.50 & $25.00-34.00$ \\
\hline Conscientiousness & - & 200 & - & 31.500 & 7.189 & 34.00 & $28.00-37.00$ \\
\hline Neuroticism & - & 200 & - & 26.020 & 8.339 & 26.00 & $19.00-32.00$ \\
\hline Openness & - & 200 & - & 23.620 & 4.191 & 24.00 & $21.00-27.00$ \\
\hline Negative valance & - & 200 & - & 11.080 & 4.480 & 10.00 & $7.00-14.00$ \\
\hline
\end{tabular}


According to Table 3, model 1/step 3 accounts for approximately $35.1 \%$ of the change in extroversion. Model $1 /$ step 3 is significant at the 5\% significance level. Age, openness, and RSES scores have statistically significant effects on extroversion. Model 1/step 1 accounts for approximately $21.3 \%$ of the change in openness. Model $1 /$ step
1 is significant at the $5 \%$ significance level. Only extroversion has a statistically significant effect on openness.

Figure 3 demonstrates pre-operative and one year post-operative images of a sample patient (Figures $3 \mathrm{a}-\mathrm{f}$ ).

\section{(a) Control}

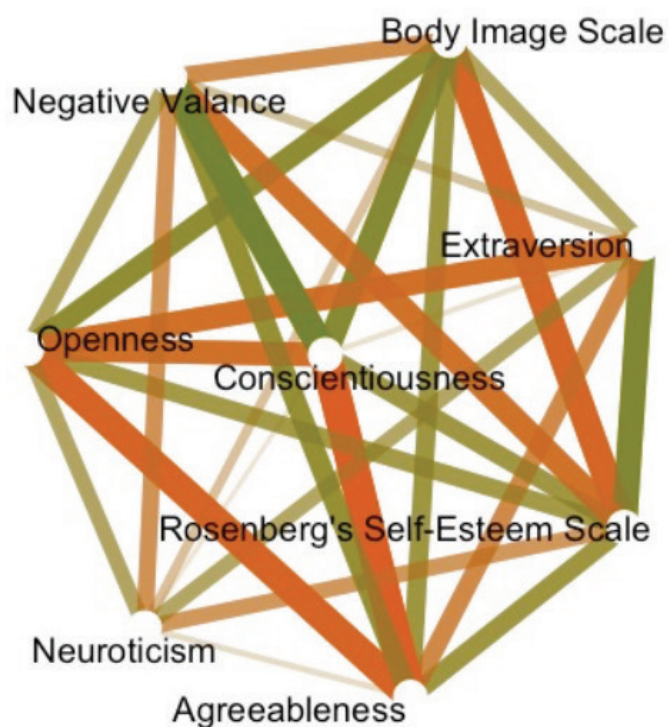

\section{(b) Patients}

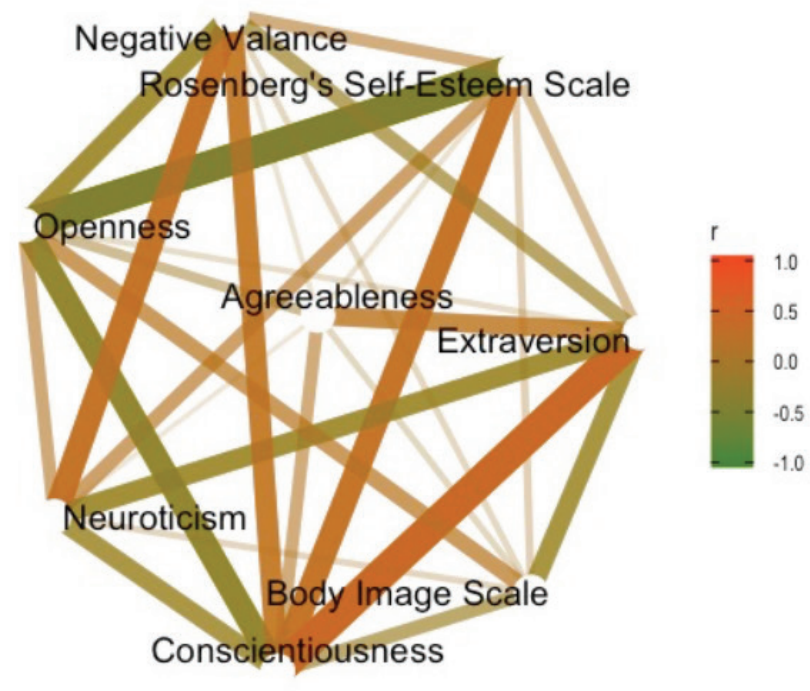

Figure 2. Pearson's correlation between scales according to (a) control and (b) patients

Table 2. Comparisons of study subjects (patients vs control) by using Independent-Samples t-test

\begin{tabular}{|c|c|c|c|c|c|c|}
\hline & Group & $\mathbf{n}$ & $\overline{\mathbf{x}}$ & s & $\mathbf{t}$ & p-value \\
\hline \multirow{2}{*}{ Age } & Control & 120 & 28.333 & 6.299 & \multirow{2}{*}{-2.041} & \multirow{2}{*}{0.051} \\
\hline & Patients & 80 & 30.800 & 5.297 & & \\
\hline \multirow{2}{*}{ Education (years) } & Control & 120 & 16.033 & 2.810 & \multirow{2}{*}{3.182} & \multirow{2}{*}{0.053} \\
\hline & Patients & 80 & 15.400 & 1.984 & & \\
\hline \multirow{2}{*}{ Rosenberg's Self-Esteem Scale } & Control & 120 & 0.947 & 0.724 & \multirow{2}{*}{0.390} & \multirow{2}{*}{0.697} \\
\hline & Patients & 80 & 0.900 & 0.287 & & \\
\hline \multirow[t]{2}{*}{ Body Cathexis Scale } & Control & 120 & 92.866 & 36.005 & \multirow{2}{*}{-2.173} & \multirow{2}{*}{0.032} \\
\hline & Patients & 80 & 107.950 & 30.717 & & \\
\hline \multirow[t]{2}{*}{ Extroversion } & Control & 120 & 30.933 & 6.232 & \multirow{2}{*}{-3.087} & \multirow{2}{*}{0.003} \\
\hline & Patients & 80 & 34.250 & 3.295 & & \\
\hline \multirow{2}{*}{ Agreeableness } & Control & 120 & 30.000 & 6.383 & \multirow{2}{*}{1.165} & \multirow{2}{*}{0.247} \\
\hline & Patients & 80 & 28.400 & 7.221 & & \\
\hline \multirow{2}{*}{ Conscientiousness } & Control & 120 & 32.466 & 7.731 & \multirow{2}{*}{1.661} & \multirow{2}{*}{0.100} \\
\hline & Patients & 80 & 30.050 & 6.097 & & \\
\hline \multirow{2}{*}{ Neuroticism } & Control & 120 & 25.666 & 8.193 & \multirow{2}{*}{-0.517} & \multirow{2}{*}{0.606} \\
\hline & Patients & 80 & 26.550 & 8.631 & & \\
\hline \multirow{2}{*}{ Openness } & Control & 120 & 22.266 & 4.333 & \multirow{2}{*}{-4.287} & \multirow{2}{*}{$<0.001$} \\
\hline & Patients & 80 & 25.650 & 3.025 & & \\
\hline \multirow{2}{*}{ Negative valance } & Control & 120 & 10.500 & 4.855 & \multirow{2}{*}{-1.598} & \multirow{2}{*}{0.113} \\
\hline & Patients & 80 & 11.950 & 3.741 & & \\
\hline
\end{tabular}



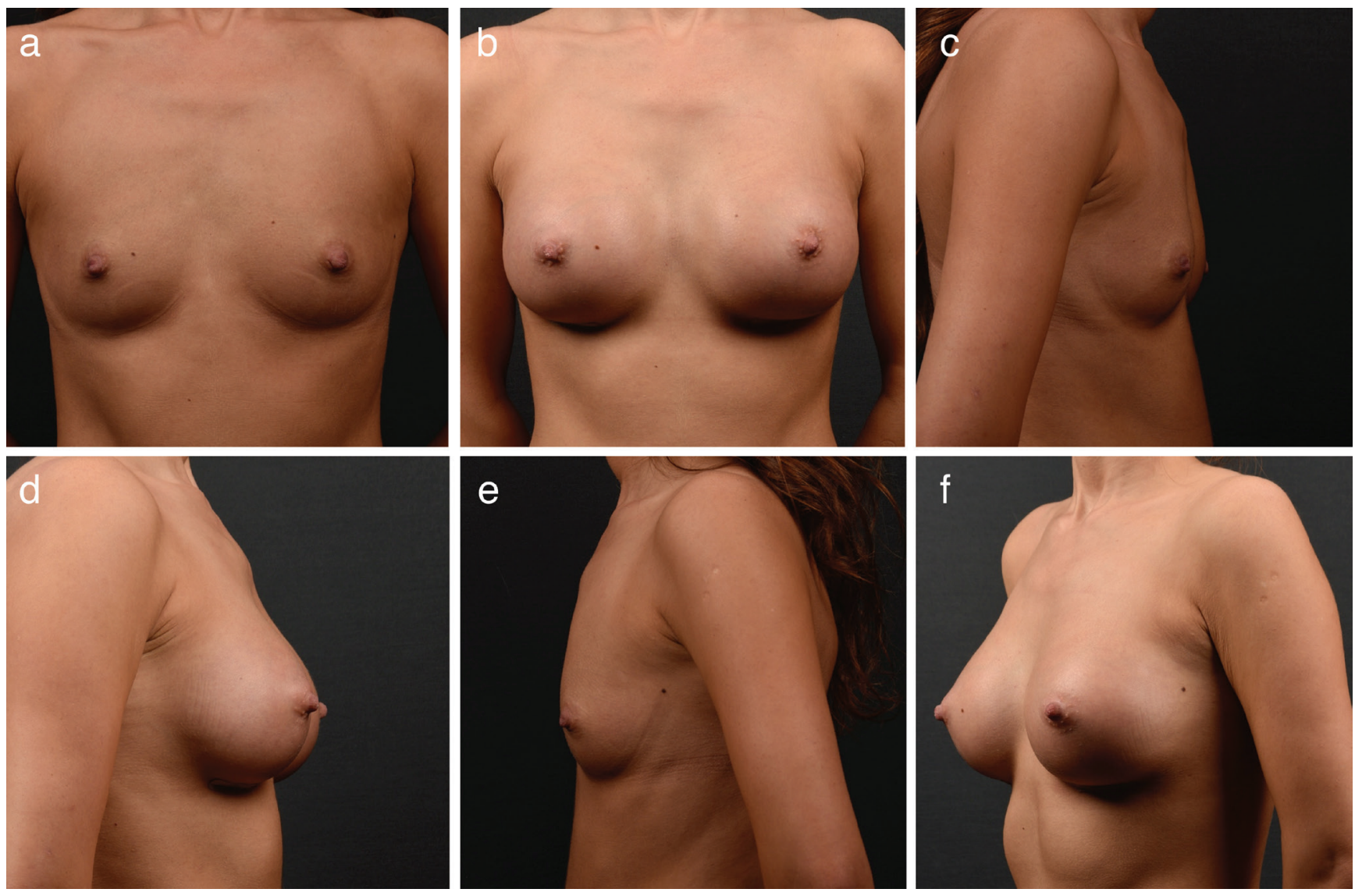

Figure 3. a. Preoperative frontal image of a sample patient. b. Postoperative frontal image of a sample patient. c. Preoperative lateral image of a sample patient (right side). d. Postoperative lateral image of a sample patient (right side). e. Preoperative lateral image of a sample patient (left side) f. Postoperative lateral image of a sample patient (left side) (33-year-old female patient; photo was taken 12 months after operation)

Table 3. Results of Step-Wise regression analysis

\begin{tabular}{|c|c|c|c|c|c|c|c|c|c|c|}
\hline & & \multicolumn{4}{|c|}{ Model 1 (Extraversion) } & \multicolumn{5}{|c|}{ Model 2 (Openness) } \\
\hline & & B & s.e. & $\mathbf{t}$ & p-value & & B & s.e. & $\mathbf{t}$ & p-value \\
\hline \multirow{3}{*}{ Step 1} & Constant & 17.977 & 2.812 & 6.393 & $<0.001$ & (Constant) & 12.230 & 2.240 & 5.460 & 0.000 \\
\hline & Openness & 0.605 & 0.117 & 5.158 & $<0.001$ & Extraversion & 0.353 & 0.068 & 5.158 & 0.000 \\
\hline & Constant & 24.088 & 3.173 & 7.591 & $<0.001$ & - & - & - & - & - \\
\hline \multirow{3}{*}{ Step 2} & Openness & 0.463 & 0.118 & 3.922 & $<0.001$ & - & - & - & - & - \\
\hline & Rosenberg's Self-Esteem Scale & -2.971 & 0.841 & -3.533 & $<0.001$ & - & - & - & - & - \\
\hline & Constant & 17.976 & 3.844 & 4.676 & $<0.001$ & - & - & - & - & - \\
\hline \multirow{3}{*}{ Step 3} & Openness & 0.464 & 0.114 & 4.055 & $<0.001$ & - & - & - & - & - \\
\hline & Rosenberg's Self-Esteem Scale & -2.748 & 0.820 & -3.350 & 0.001 & - & - & - & - & - \\
\hline & Age & 0.200 & 0.075 & 2.655 & 0.009 & - & - & - & - & - \\
\hline $\mathbf{n}$ & & \multicolumn{4}{|c|}{100} & \multicolumn{5}{|c|}{100} \\
\hline df & & \multicolumn{4}{|c|}{$(3.96)$} & \multicolumn{5}{|c|}{$(1.98)$} \\
\hline F statistic & & \multicolumn{4}{|c|}{17.294} & \multicolumn{5}{|c|}{26.602} \\
\hline p-value & & \multicolumn{4}{|c|}{$<0.001$} & \multicolumn{5}{|c|}{$<0.001$} \\
\hline $\mathbf{R}^{2}$ & & \multicolumn{4}{|c|}{0.351} & \multicolumn{5}{|c|}{0.213} \\
\hline
\end{tabular}




\section{Discussion and Conclusion}

Cosmetic surgery is considered to improve the quality of life of women who undergo breast surgery for various reasons. Longitudinal studies that investigated the effects of breast augmentation on the psychological status of women have also found that the surgery improved their psychosocial and sexual well-being, increased their satisfaction level with their breasts, and enhanced their body image, which consequently boosted their self-esteem, decreased depressive symptomatology, and alleviated their eating disorders (4-6). However, few studies have focused on the personality traits of women who undergo breast augmentation surgery solely for cosmetic reasons. Furthermore, there were no previous studies comparing personality traits between women who underwent breast augmentation surgery and a control group.

The concept of personality shifts from similarities to differences between individuals over time (14). The five-factor model of personality was developed to define variations between individuals to discover consistent cognitive, emotional, and behavioral patterns, otherwise known as traits (17). The taxonomic model has five orthogonal factors in English, in both self- and peer-rated measures, that can be applied regardless of the factor analytic method (19). These factors are surgency (extroversion), agreeableness, conscientiousness, emotional instability (neuroticism), and intellect (culture/openness). These five factors have been reported to be consistent with almost all personality theories. These five factors are extroversion, agreeableness, conscientiousness, neuroticism, and openness, respectively (20).

As previously mentioned, studies that focus on the personality of women who undergo breast augmentation surgery are quite limited. Previous studies reported that women who underwent breast augmentation were more likely to suffer from depression and anxiety and have a neurotic personality (21-24). Neuroticism is one of the main temperament types and is characterized by a tendency to react in an inappropriate and often excessive manner in stressful situations (13, 25). Thus, individuals with higher levels of neuroticism are reported to have behavioral disengagement and feelings of helplessness (25). Davis et al. (26) reported an association between neuroticism and undergoing aesthetic surgery, including breast augmentation. Groenman (27) assessed women who received breast augmentation and reported that neurotic behavior decreased after surgery. A relatively recent study assessed levels of neuroticism and life satisfaction before and after breast augmentation surgery. In this study, Zaborski et al. (2) found that there was no significant change in neuroticism levels before and after surgery, based on the Big Five model.

Considering the inconsistency in the results of previous studies, we wondered whether there could be a pre-acceptance of neuroticism for women who undergo breast augmentation surgery. While previous studies have focused on determining the level of neuroticism before and after breast augmentation surgery, our study focused on a comparison between women who undergo the surgery and women who do not. We hypothesized that the claim that women who undergo breast augmentation have higher levels of neuroticism may be the result of stigmatization. To test this hypothesis, we compared the personality traits of women who underwent breast augmentation surgery with those of age- and education-level-matched women who did not have the surgery. We found that the extroversion score was higher in the breast augmentation group, as compared with the control group. Unlike neuroticism, extroversion is associated with positive affectivity $(11,13,28)$, and extroverted people are considered to be agreeable in social interactions (29). Moreover, low extraoversion and high neuroticism levels are reported to be associated with a tendency to experience depression and anxiety disorders (30). The other personality dimension that differed in the present study was openness. The mean openness score was also found to be higher in the breast augmentation group. Openness is considered to be part of the personality pertaining to flexibility $(13,31)$. Higher scores on this measure were found to be positively associated with higher self-esteem and positive affect. Openness to experiences is also associated with psychological wellbeing and better coping strategies (32). The other dimensions of personality were found to be similar between groups.

These results reveal that women who underwent breast augmentation surgery have higher levels of advantageous personality traits in terms of psychological well-being, social interactions, and coping strategies. Based on this, we suggest that beliefs regarding the personality traits of women who undergo breast augmentation surgery may be influenced by myth and stigmatization. Moreover, the breast augmentation group scored higher on the BCS compared with the control group. No significant correlation was found between the personality traits of extroversion and openness to experience and the BCS score in the breast augmentation group. Moreover, the regression analysis showed no significant associations between extroversion and openness and BCS score. An explanation for these results might be that these positive personality traits are independent of body satisfaction.

Although we attempted to determine the associations between personality dimensions and other variants, such as the BCS, the higher extroversion and openness to experience scores may be dependent on surgical success. Thus, the cross-sectional design of the present study can be considered a limitation.

In conclusion, we argue that there may be a presupposition, based on stigma, that women who undergo breast augmentation surgery are more neurotic than those who do not. Consequently, this may influence the outcomes of studies testing the personalities of these women. Our results indicate that the breast augmentation group after having undergone surgery had more positive personality traits than the control group. Further studies are needed to confirm these results.

Ethics Committee Approval: The study was approved by the Tekirdağ Namık Kemal University Non-Invasive Clinical Researches Ethics Committee (date: 30.05.2019/approval no: 2019.101.06.22).

Informed Consent: All participants gave written informed consent before participating in the study. Additional permissions were obtained from patients whose images were used in the present study.

Peer-review: Externally peer-reviewed.

\section{Authorship Contributions}

Conception: G.Ö.; Design: G.Ö., E.B., M.B.; Supervision: E.B., Y.A., M.B.; Data Collection and/or Processing: Analysis and/or Interpretation: G.Ö., E.B.; Literature Review: G.Ö., Y.A., M.B.; Writing: E.B., Y.A., M.B.; Critical Review: E.B., Y.A., M.B.

Conflict of Interest: No conflict of interest was declared by the authors.

Financial Disclosure: The authors declare that this study received no financial support. 


\section{References}

1. Gabriel A, Maxwell GP. Implant selection in the setting of prepectoral breast reconstruction. Gland Surg 2019; 8: 36-42. (PMID:30842926) [Crossref]

2. Zaborski D, Rzepa T, Pastucha M, Modrzejewski A, Grzesiak W. Neuroticism level and life satisfaction in women undergoing breast augmentation surgery (a preliminary report). Aesthetic Plast Surg 2019; 43: 521-530. (PMID: 30725194) [Crossref]

3. No authors listed. The American Society for Aesthetic Plastic Surgery's Cosmetic Surgery National Data Bank: Statistics 2018. Aesthet Surg J 2019; 39: 1-27. (PMID: 31226205) [Crossref]

4. McCarthy CM, Cano SJ, Klassen AF, Scott A, Van Laeken N, Lennox PA, et al. The magnitude of effect of cosmetic breast augmentation on patient satisfaction and health-related quality of life. Plast Reconstr Surg 2012; 130: 218-223. (PMID: 22743886) [Crossref]

5. Penaud A, De Mortillet S. Evaluation of the psychological benefits of breast augmentation for aesthetic purposes. Results of a multicenter prospective study of a series of 181 patients]. Ann Chir Plast Esthet 2013; 58: 10-17. (PMID: 23122532) [Crossref]

6. Saariniemi KM, Helle MH, Salmi AM, Peltoniemi HH, Charpentier P, Kuokkanen HOM. The effects of aesthetic breast augmentation on quality of life, psychological distress, and eating disorder symptoms: a prospective study. Aesthetic Plast Surg 2012; 36: 1090-1095. (PMID: 22648598) [Crossref]

7. Larson K, Gosain AK. Cosmetic surgery in the adolescent patient. Plast Reconstr Surg 2012; 129: 135e-141e. (PMID: 22186528) [Crossref]

8. Coombs DM, Grover R, Prassinos A, Gurunluoglu R. Breast augmentation surgery: Clinical considerations. Cleve Clin J Med 2019; 86: 111-122. (PMID: 30742581) [Crossref]

9. McAdams DP, Olson BD. Personality development: continuity and change over the life course. Annu Rev Psychol 2010; 61: 517-542. (PMID: 19534589) [Crossref]

10. Ben-Ari A, Lavee Y. Dyadic characteristics of individual attributes: attachment, neuroticism, and their relation to marital quality and closeness. Am J Orthopsychiatry 2005; 75: 621-631. (PMID: 16262519) [Crossref]

11. Pamir M. Don't worry, be happy? Neuroticism, trait-consistent affect regulation, and performance. J Pers Soc Psychol 2005; 89: 449-461. (PMID: 16248724) [Crossref]

12. Meier BP, Robinson MD, Wilkowski BM. Turning the other cheek. Agreeableness and the regulation of aggression-related primes. Psychol Sci 2006; 17: 136-142. (PMID: 16466421) [Crossref]

13. Saulsman LM, Page AC. The five-factor model and personality disorder empirical literature: a meta-analytic review. Clin Psychol Rev 2004; 23 : 1055-1085. (PMID: 14729423) [Crossref]

14. Groenman NH. Psychological effects of aesthetic surgical breast procedures - a preliminary report. Chir Plast 1978; 45: 471-476. [Crossref]

15. Gençöz T, Öncül Ö. Examination of personality characteristics in a turkish sample: development of basic personality traits inventory. J Gen Psychol 2012; 139: 194-216. (PMID: 24837020) [Crossref]

16. Rosenberg M. Society and the adolescent self-image. Princeton, NJ: Princeton University Press; 1965. [Crossref]
17. Cuhardaroglu F. Self-esteem in adolescents. Spec thesis Hacettepe Univ Med Fac Ankara, Turkey, 1986. [Crossref]

18. Secord PF, Jourard SM. The appraisal of body-cathexis: body-cathexis and the self. J Consult Psychol 1953; 17: 343-347. (PMID: 13109086) [Crossref]

19. De Fruyt F, De Clercq BJ, van de Wiele L, Van Heeringen K. The validity of Cloninger's psychobiological model versus the five-factor model to predict DSM-IV personality disorders in a heterogeneous psychiatric sample: domain facet and residualized facet descriptions. J Pers 2006; 74 : 479-510. (PMID: 16529584) [Crossref]

20. Goldberg LR. An alternative "description of personality": the big-five factor structure. J Pers Soc Psychol 1990; 59: 1216-1229. (PMID: 2283588) [Crossref]

21. Cook LS, Daling JR, Voigt LF, deHart MP, Malone KE, Stanford JL, et al. Characteristics of women with and without breast augmentation. JAMA 1997; 277: 1612-1617. (PMID: 9168291) [Crossref]

22. Fryzek JP, Weiderpass E, Signorello LB, Hakelius L, Lipworth L, Blot WJ, et al. Characteristics of women with cosmetic breast augmentation surgery compared with breast reduction surgery patients and women in the general population of Sweden. Ann Plast Surg 2000; 45: 349-356. (PMID: 11037154) [Crossref]

23. Kjøller K, Hölmich LR, Fryzek JP, Jacobsen PH, Friis S, McLaughlin JK, et al. Characteristics of women with cosmetic breast implants compared with women with other types of cosmetic surgery and population-based controls in Denmark. Ann Plast Surg 2003; 50: 6-12. (PMID: 12545102) [Crossref]

24. Swanson E. Prospective outcome study of 225 cases of breast augmentation. Plast Reconstr Surg 2013; 131: 1158-1166. (PMID: 23629096) [Crossref]

25. Eysenck HJ. Behaviourism and clinical psychiatry. Int J Soc Psychiatry 1985; 31: 163-169. (PMID: 4044149) [Crossref]

26. Davis D, Shaver PR, Vernon ML. Attachment style and subjective motivations for sex. Pers Soc Psychol Bull 2004; 30: 1076-1090. (PMID: 15257790) [Crossref]

27. Groenman NH. Psychological effects of aesthetic surgical breast procedures. Chir Plast 1978; 4: 95-101. [Crossref]

28. Lucas RE, Diener E, Grob A, Suh EM, Shao L. Cross-cultural evidence for the fundamental features of extraversion. J Pers Soc Psychol 2000; 79: 452-468. (PMID: 10981846) [Crossref]

29. Côté S, Moskowitz DS. On the dynamic covariation between interpersonal behavior and affect: prediction from neuroticism, extraversion, and agreeableness. J Pers Soc Psychol 1998; 75: 1032-1046. (PMID: 9825533) [Crossref]

30. Jorm AF, Christensen H, Henderson AS, et al. Predicting anxiety and depression from personality: Is there a synergistic effect of neuroticism and extraversion? J Abnorm Psychol 2000; 109: 145-149. (PMID: 10740946) [Crossref]

31. Costa PT, McCrae RR. Bridging the gap with the five-factor model. Personal Disord 2010; 1: 127-130. (PMID: 22448624) [Crossref]

32. Bouchard G. Cognitive appraisals, neuroticism, and openness as correlates of coping strategies: an integrative model of adaptation to marital difficulties. Can J Behav Sci 2003; 35: 1-12. [Crossref] 